See discussions, stats, and author profiles for this publication at: https://www.researchgate.net/publication/269050270

\title{
Wavelet Analysis of Equatorial Electrojet (EEJ) Data Over East and West Coasts of South America
}

\section{Conference Paper · August 2009}

DOI: 10.1190/sbgf2009-380

CITATIONS

4 authors, including:

Eurico de Paula

National Institute for Space Research, Brazil

196 PUBLICATIONS 3,906 CITATIONS

SEE PROFILE
Clezio M. Denardini

National Institute for Space Research, Brazil 129 PUBLICATIONS 582 CITATIONS

SEE PROFILE

Some of the authors of this publication are also working on these related projects:

TIDS COMPREHENSIVE STUDY View project 


\section{Wavelet Analysis of Equatorial Electrojet (EEJ) Data Over East and West Coasts of South America}

Esayas Belay Shume, Eurico Rodrigues de Paula, Clezio Marcos Denardini, and Nalin Babulal Trivedi

Instituto Nacional de Pesquisas Espaciais, São José dos Campos, SP, Brazil

\section{Copyright 2009, SBGf - Sociedade Brasileira de Geofísica}

This paper was prepared for presentation during the $11^{\text {th }}$ International Congress of the Brazilian Geophysical Society held in Salvador, Brazil, August 24-28, 2009.

Contents of this paper were reviewed by the Technical Committee of the $11^{\text {th }}$ International Congress of the Brazilian Geophysical Society and do not necessarily represent any position of the SBGf, its officers or members. Electronic reproduction or storage of any part of this paper for commercial purposes without the written consent of the Brazilian Geophysical Society is prohibited.

\begin{abstract}
We have applied a wavelet analysis technique on the quiet-time equatorial magnetic field perturbation measurements (signature of the equatorial electrojet) from São Luís (Brazil) and Jicamarca (Peru), to study longitudinal, seasonal, and solar cycle variabilities of the equatorial electrojet over the East and West coasts of South America.
\end{abstract}

\section{Introduction}

The equatorial electrojet (EEJ) is a strong electric current owing from about 90 to $115 \mathrm{~km}$ of altitude in the Earth's equatorial ionosphere region where the magnetic dip angle is small. The regular course of the current is eastward during day-time and westward at night. EEJ can cause a net detection of about $150 \mathrm{nT}$ on ground-based magnetometers during solar maximum conditions.

EEJ is driven by a combination of: Horizontal geometry of the geomagnetic field in the proximity of the magnetic equator, anisotropy in ionospheric conductivities, the confinement of the Hall conductivity in a finite slab, solar tide driven dynamo, and the resulting horizontal and vertical polarization electric field [1, 2].

\section{Objectives}

Zonal electric fields of the equatorial ionosphere depends on season and solar cycle [3]. Likewise, the magnitude of EEJ is highly variable with season and solar cycle. The magnitude of EEJ is generally higher during solar maximum conditions compared to solar minimum conditions, and the strength of EEJ has also a seasonal dependence [2, 4].

Here, we address the following issues which are related to quiet-time EEJ:

1. Analysis of seasonal and solar cycle variability in the magnitude of EEJ in the West and East Coasts of South America.
2. Longitudinal variabilities of the strength of EEJ between the East and West coasts of South America has been reported by [5]. Here, we investigate longitudinal variation of the varibilities for different season and solar activity conditions.

3. What are the roles of ionospheric conductivities and electric fields for the seasonal, solar cycle and longitudinal variabilities of EEJ?

\section{Data Analysis}

Ground-based magnetic field measurements for the years 2001 (solar maximum) and 2008 (solar minimum) obtained from São Luís and Eusébio magnetometer stations, Brazil (East coast of South America), and Jicamarca and Piura, Peru (West coast of South America) magnetometer stations will be used for our study.

Magnetic field data from São Luís and Jicamarca were analyzed to address the science questions mentioned in Section 2. To identify the dominant periodicities of the EEJ and thereby understand EEJ variabilities, the wavelet (Mexican Hat) analysis technique [6, 7] was employed.

An example of magnetic field signal for our wavelet analysis is shown in Figure 1 . The data shows 30 days of net magnetic field (caused by EEJ) data measured by ground-based magnetometer in Jicamarca and Piura (Peru) for the year 2001, which can be considered as a solar maximum year. The figure shows data from equinox (March and September) and solstice (January, June, and December) seasons.

\section{Acknowledgments}

E. B. Shume is supported by FAPESP under project No. 2007/08185-9.

\section{References}

[1] Richmond, A. D., Equatorial electrojet - I. Development of a model including winds and instabilities, J. Atmos. Terr. Phys., 35 , 6, 1083, 1973.

[2] Forbes, J. M., The equatorial electrojet, Rev. Geophys., 19 , 469-504, 1981.

[3] Fejer, B. G., D. T. Farley, R. F.Woodman, and C. Calderon, Dependence of equatorial $F$ region vertical drifts on season and solar cyles, J. Geophys. Res., 80 , 10, 1979.

[4] Chandra, H., H. S. S. Sinha, and R. G. Rastogi, Equatorial electrojet studies from rocket and ground 
measurements, Earth Planets Space, 52, 111 - 120, 2000.

[5] Rastogi, R. G., H. Chandra, D. Chakrabarty, K. Kitamura, and K. Yumoto, Dayto-day correlation of equatorial electrojet at two stations separted by $2000 \mathrm{~km}$, Ann. Geophys, 25, 875 - 880, 2007.

[6] Kumar, P. and E. Foufoula-Georgiou, Wavelet analysis for geophysical applications, Reviews of Geophysics, 35, 4, 1997.

[7] Torrence, C. and G. P. Compo, A practical guide to wavelet analysis, Bulletin of the American Meteorological Society, 79, 1, 1998.

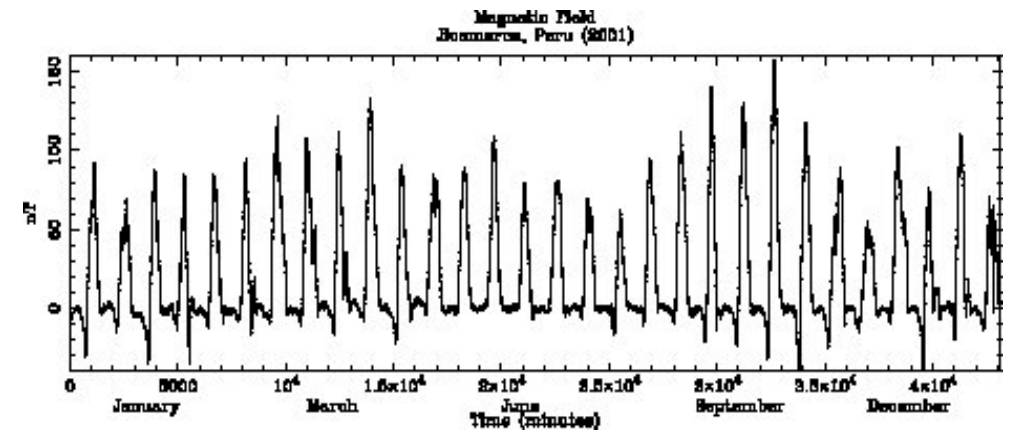

Figure 1: Ground-based magnetic field perturbation measurements for solar maximum year 2001 in Jicamarca, Peru. 


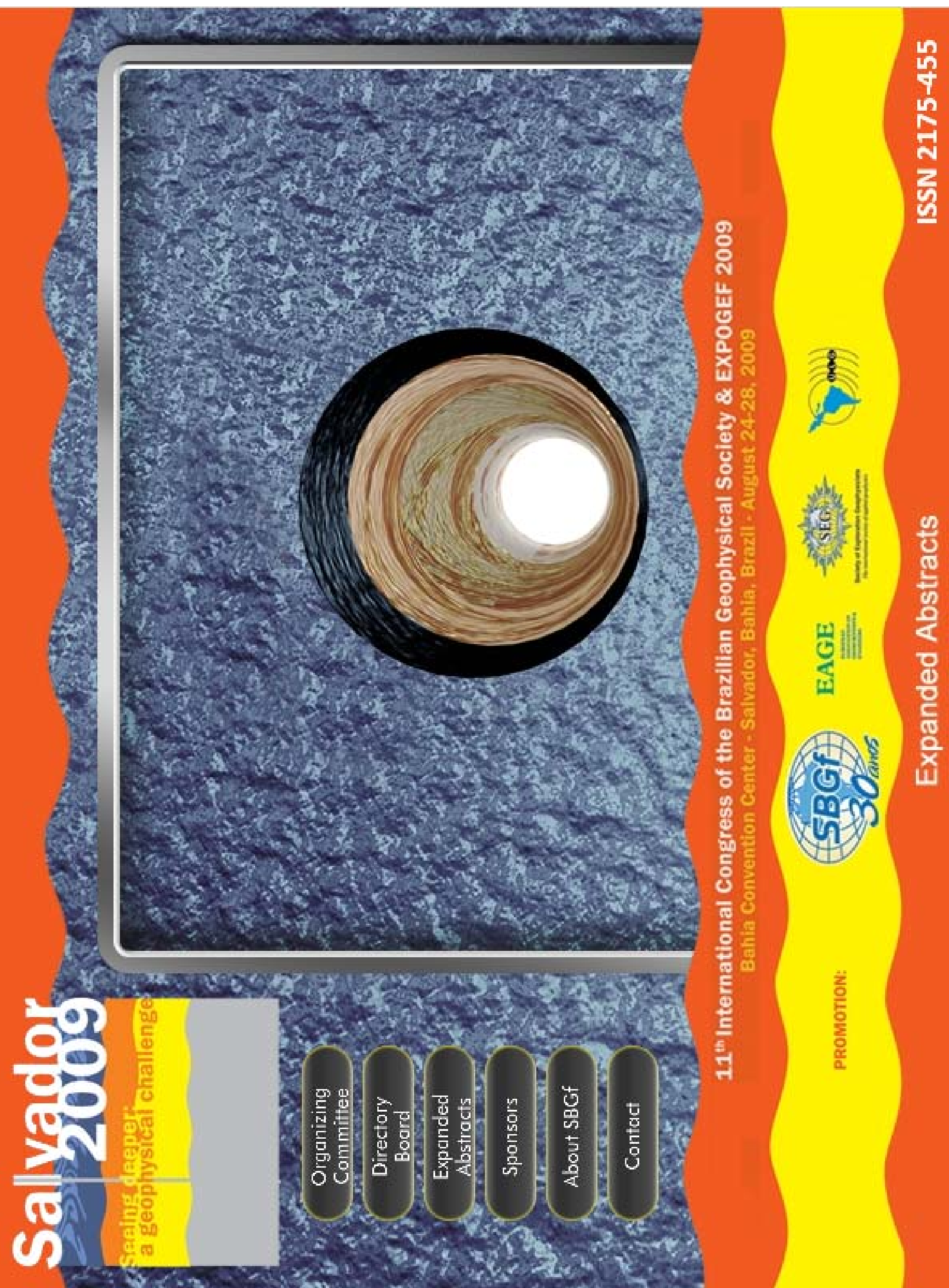

